\title{
Auxotypes and serogroups of penicillinase producing and non-producing strains of Neisseria gonorrhoeae isolated in Franceville, Gabon
}

\author{
F YVERT, * E FROST,* M GUIBOURDENCHE, $+\mathrm{J}$ Y RIOU, + AND B IVANOFF* \\ From the ${ }^{*}$ Laboratoire de Microbiologie, Centre International de Recherches Médicales de Franceville, \\ Franceville, Gabon, and the +Laboratoire des Neisseria, Unité d'Ecologie Bactérienne, Institut Pasteur, \\ Paris, France
}

SUMMARY The auxotypes and serogroups of 250 consecutive isolates of Neisseria gonorrhoeae from Franceville, Gabon, including 33 penicillinase producing (PPNG) strains, were identified and the results tabulated for four periods. The PPNG and certain non-PPNG strains were isolated in clusters against a relatively stable pattern of non-PPNG biotypes. Most of the non-PPNG strains were non-requiring or proline requiring strains of serogroup WII or non-requiring strains that could not be grouped with commercially available antisera. No strain requiring arginine, hypoxanthine, and uracil was observed. The PPNG strains were all serogroup WI or ungroupable and non-requiring or proline or arginine dependent auxotypes. Only one non-PPNG strain required proline or arginine and was not serogroup WII.

\section{Introduction}

The potential of the gonococcus to cause sterility ${ }^{12}$ and other complications ${ }^{3}$ makes surveillance of strains important, ${ }^{4}$ particularly in the case of penicillinase producing Neisseria gonorrhoeae (PPNG) strains, treatment failures of which might increase the risk of complications.

Previous studies have shown that $\mathbf{N}$ gonorrhoeae is a commonly observed pathogen in Franceville, Gabon $^{5}$ and in neighbouring African states. ${ }^{6-8}$ Our previous study showed that $5.5 \%$ of non-selected pregnant women were culture positive. ${ }^{5}$ The strains isolated in Franceville are of particular interest as they came from a semirural African population far from the capital city. To obtain more insight into their epidemiology, we auxotyped and serogrouped PPNG and non-PPNG strains.

\section{Patients, materials, and methods}

ORIGIN OF STRAINS OF $N$ GONORRHOEAE We have already described the isolation of 241 strains, 153 from men with urethral discharge and 88

Address for reprints: Dr B Ivanoff, Laboratoire de Microbiologie, Centre International de Recherches Médicales de Franceville, BP 769, Franceville, Gabon

Accepted for publication 11 August 1984 from women, of whom 23 were pregnant and considered to be asymptomatic. ${ }^{5}$ In addition to those already reported, nine strains were of ophthalmic origin, seven from newborn children and two from adults. Of the total 250 strains, 33 (13\%) were resistant to penicillin and produced a penicillinase. All strains were isolated between September 1980 and November 1982.

\section{ISOLATION AND IDENTIFICATION}

We isolated, identified, and stored strains according to standard procedures that have been described previously. ${ }^{59}$

\section{IDENTIFICATION OF PENICILLINASE}

PRODUCING STRAINS

We used the disc diffusion procedure to make antibiograms, ${ }^{10}$ and an iodometric gel procedure modified for $N$ gonorrhoeae to identify $\beta$-lactamases. ${ }^{11}$

\section{AUXANOGRAPHIC TYPING}

We performed auxotyping by growing isolates of $N$ gonorrhoeae on chemically defined media as described by Catlin ${ }^{12}$ and omitting singly or in combination, proline, arginine, uracil, methionine, or hypoxanthine. A negative control plate lacking cysteine and cystine was also used. 


\section{SEROGROUPING}

We performed serogrouping using reagents against WI and WII that are available commercially (New Horizons Diagnostics, Columbia, Maryland, USA). ${ }^{1314}$ Staphylococci sensitised with polyclonal group specific antisera to $N$ gonorrhoeae were used. One drop of antiserum was mixed on a special glass plate with one drop of a boiled suspension ( $1 \%$ weight per volume) of the gonococcal strain under investigation. Both serogroups were tested simultaneously in separate reactions and, after being mixed for two minutes, the suspensions were observed for agglutination under oblique transmitted light. The manufacturer's control WI and WII preparations were examined at the same time.

STATISTICAL ANALYSIS

The $\chi^{2}$ test was used for stastical analysis.

\section{Results}

The 250 isolates included 217 non-PPNG strains from 129 men, 80 women, and eight conjunctival secretions (from one adult and seven neonates) and 33 PPNG strains from 21 men, 11 women, and one eye infection in an adult. No PPNG strains were found in the asymptomatic pregnant women studied.

The strains were all auxotyped and serogrouped. Figure 1 shows that $155(71 \cdot 4 \%)$ non-PPNG strains belonged to the WII serogroup, $25(11 \cdot 5 \%)$ to the WI serogroup, and $37(17 \cdot 1 \%)$ were not groupable with commercially available reagents. All the PPNG strains belonged to group WI (11 (33\%)) or were ungroupable $(22(67 \%))$. Most of the isolates had no

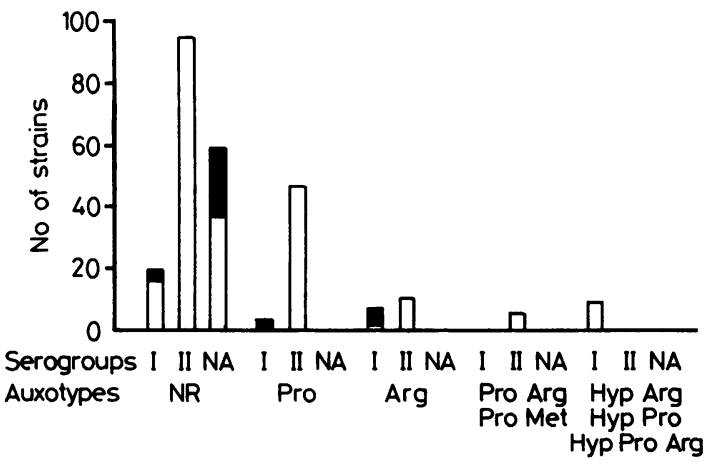

FIG 1 Incidence of combinations of auxotypes and serogroups in 33 PPNG (black columns) and 217 nonPPNG (empty columns) strains. (I $=W I, I I=W I I$, and $N A=$ non-agglutinating serogroups. $N R=$ nonrequiring, Pro $=$ proline requiring, $A r g=$ arginine requiring, Met $=$ methionine requiring,

Hyp = hypoxanthine requiring auxotypes). special nutritional requirements. The PPNG strains that were prototrophic usually did not agglutinate with either serogroup WI or WII reagents, although a few isolates could be classed as WI. On the other hand, most of the prototrophic non-PPNG strains were in serogroup WII. The strains with nutritional requirements formed clear patterns. All could be classified as WI or WII. Isolates classified as serogroup WI were (with one exception) either PPNG strains and required proline or arginine, or were nonPPNG strains and required at least two nutrients, of which one was hypoxanthine. All the WII isolates were non-PPNG strains and required proline or arginine, or both, but not hypoxanthine.

Comparison of strains from men with those from symptomatic women showed no appreciable differences in incidence of auxotypes or serogroups. Strains from asymptomatic pregnant women did not differ appreciably from those from symptomatic (with irregular vaginal discharge observed on examination with a speculum) pregnant women who presented during the same period. Too few ophthalmic strains were isolated to allow statistical analysis, but they fell into the three major combinations of auxotype and serogroup and thus did not appear to be unusual.

Figure 2 shows the 250 isolates divided into four equal groups in chronological order. The incidence of most of the combinations of auxotypes and serogroups, even the minor ones, remained relatively constant during the period in which the 250 isolates were taken, with a superimposition of outbreaks of other (notably PPNG) strains on the general pattern. All five of the arginine requiring group WI PPNG strains appeared in the first period, whereas 27 of the 28 other PPNG strains were seen in the last period. The strains requiring hypoxanthine also appeared in a cluster towards the end of the study. The outbreak of PPNG strains in the last period was accompanied by a significant decrease $(p<0 \cdot 001)$ in the proportion of non-PPNG strains that were prototrophic and in group WII.

It was difficult to trace sexual contacts for culture or treatment. Thus the $\mathbf{2 5 0}$ strains included only four known couples, of which two had similar and two different strains. Of the seven neonates with eye infections, the mothers of only two could be examined and similar strains isolated. The other mothers were treated empirically. Eight people presented twice during the study, six of whom yielded isolates with the same auxotypes and serogroups. In each case, however, the samples were taken more than two months apart and probably represented recontamination. The study included isolates from 10 European men, but only one of their acknowledged sexual partners, who was an African yielding a strain 


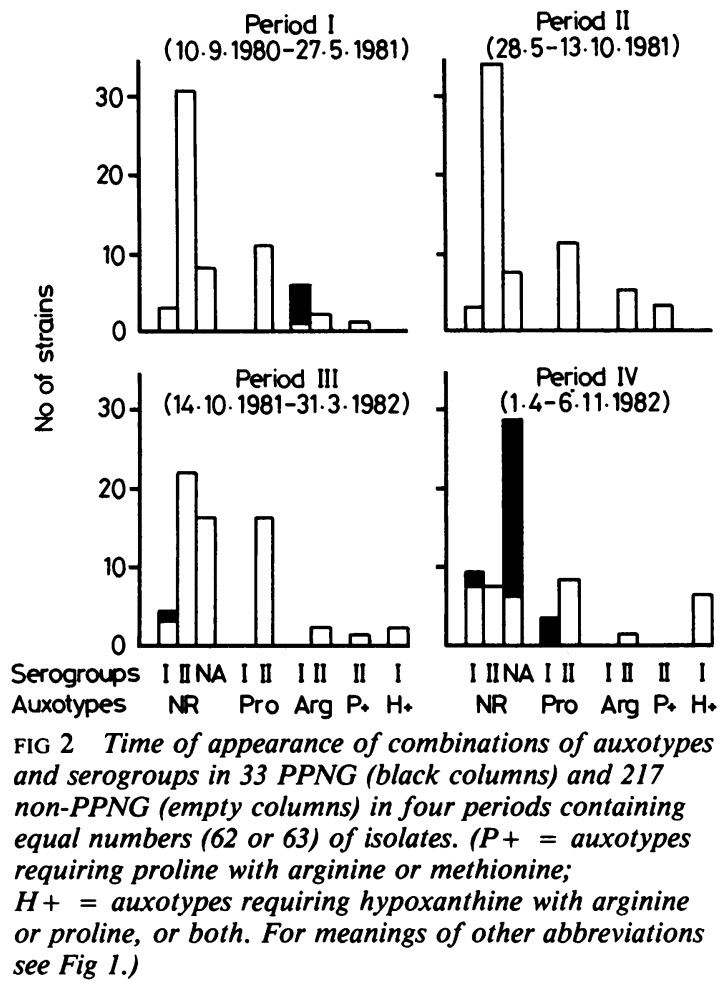

with an auxotype that differed from that of the index case. All of these 10 isolates were of the most common auxotypes and serogroups and probably represented local strains.

\section{Discussion}

We have reported auxanographic profiles, serogroups, and penicillinase production of 250 strains of $N$ gonorrhoeae isolated during 27 months in Franceville, Gabon. Few other studies have been reported linking these three traits, although they appear to have great potential in epidemiological studies. The fact that our isolates were from a relatively small population in a semirural area in a developing country, far from the capital city, enhances the interest of our findings.

The basic pattern comprised primarily non-PPNG strains classed as serogroup WII (either nonrequiring or proline dependent) or else non-requiring strains that could not be grouped. Small but constant numbers of non-requiring group WI and arginine dependent group WII strains were also seen. The most common auxotypes were the same as those reported from the Central African Republic, ${ }^{15}$ elsewhere in Africa, ${ }^{16}$ and in some Asian countries, ${ }^{17}$ but lacked the auxotype requiring arginine, hypoxanthine, and uracil that has often been found in Europe and America. ${ }^{18}$ In contrast, analysis of a limited number of non-PPNG strains from Ghana showed a predominance of proline requiring serogroup WI strains. ${ }^{19}$

Other studies of serogroups have indicated, as has ours, a predominance of group WII among nonPPNG strains. ${ }^{16}{ }^{17} \mathrm{~A}$ third group (WIII) has rarely been found in Europe and North America, but frequently in the Philippines. ${ }^{17}$ As WIII serum is not available commercially, we could not test for WIII serogroup. We did observe, however, that $17 \%$ (37) of our non-PPNG and 67\% (22) of our PPNG strains did not react with commercial WI or WII serum samples. In collaboration with the Institut Mérieux, we tried to type these strains in the nine groups of Buchanan and Hildebrandt, ${ }^{20}$ and although our group WI and WII strains could generally be typed, the ungroupable strains could not (Mynard M C, Yvert F, Armand J, unpublished observations), even with groups 8 and 9 that usually correspond with WIII. Serovars ${ }^{21}$ of our WI and WII strains examined by Dr E Sandström in Stockholm, corresponded well with our results. These strains reacted with many of the monoclonal antibodies used, whereas the ungroupable strains reacted with few of the reagents developed from European or American strains; the eight ungroupable PPNG strains that were analysed responded as WI, and 16 of the 18 non-PPNG strains as WII (Sandström E, unpublished observation).

Although PPNG strains reported from other parts of the world were of variable auxotypes and serogroups, ${ }^{1722}$ those from Africa, including those in this study, were almost always serogroup WI and nonrequiring, proline requiring, or arginine requiring auxotypes. ${ }^{161922}$ Most of our PPNG strains were non-requiring and apparently belonged to a WI type that does not react with commercially available serum, in contrast with those from other parts of Africa that reacted as WI serogroups. ${ }^{16} 1922$ It is interesting to note that, in this study, the PPNG strains requiring proline or arginine were generally of a different serogroup from the non-PPNG strains of the same auxotype. This could mean that these PPNG strains were imported or, alternatively, that transfer into WI strains is much more efficient or stable than into WII strains. The plasmid content of a few of our strains has been reported, showing African type plasmids with an occasional conjugative plasmid. ${ }^{23}$

Sudden changes appear to be a typical trait of gonococcal epidemiology. In fact, ungroupable and proline requiring PPNG strains had not been observed before period IV, when they represented 
$40 \%$ of the isolates (see fig 2). Similarly, eight hypoxanthine requiring strains appeared in a cluster without having been isolated previously. It is interesting to note that after an outbreak of five arginine requiring PPNG strains in period $I$, these strains did not reappear.

Contact tracing was, at best, very sporadic during this study and cannot be credited with any modification in strain patterns. Many factors (including the virulence of a strain, sexual behaviour, immunity and the efficiency of antibiotics) must play a major part. Small populations like that of Franceville would be excellent for studies of these factors, particularly immunity.

We thank the doctors of the Franceville Provincial Hospital, of the Caisse National de Sécurité Sociale (CNSS), and of the Grandes Endémies for their cooperation in supplying specimens. We also thank $S$ Ossari for technical help, $G$ Beville for documentation, and A Beville for secretarial help.

\section{References}

1. Weström L. Incidence, prevalence and trends of acute pelvic inflammatory disease and its consequences in industrialized countries. Am J Obstet Gynecol 1980; 138: 880-92.

2. Osoba AO. Sexually transmitted diseases in tropical Africa: a review of the present situation. British Journal of Venereal Diseases 1981; 57:89-94.

3. World Health Organisation. Neisseria gonorrhoeae and gonococcal infections. WHO Tech Rep Ser 1978; No 616:138-9.

4. Causse G. Sensibilité de Neisseria gonorrhoeae aux antibiotiques: son importance en santé publique. Proceedings of International Meeting on Tropical Microbiology, Dakar, 18-21 février 1980. Ann Microbiol (Paris) 1980; 131:83-4.

5. Yvert F, Riou JY, Frost E, Ivanoff B. Les infections gonococciques au Gabon (Haut-Ogooué). Pathol Biol (Paris) $1984 ; 32: 80-4$.

6. Nasah BT, Nguematcha R, Eyong M, Godwin S. Gonorrhea, trichomonas and candida among gravid and non gravid women in Cameroon. Int J Gynecol Obstet 1980; 18:48-52.

7. Yala F. Enquêtes préliminaires sur les infections à Neisseria gonorrhoeae à Brazzaville. Fréquence et pharmaco-sensibilité. Bull Soc Pathol Exot Filiales 1980; 73:38-48.
8. Widy-Wirski R, D'Costa J, Biddle J, Brown S. Antimicrobial susceptibility of gonococci isolated in the Central African Republic. Bull WHO 1982;60:959-63.

9. Riou JY, Guibourdenche M. Diagnostic bactériologique des espèces des genres Neisseria et Branhamella. Ann Biol Clin (Paris) 1977; 35: 73-87.

10. Riou JY, Guibourdenche M, Courvalin P. Antibiotic susceptibility testing of Neisseria gonorrhoeae by disk-agar diffusion. Ann Microbiol (Paris) 1981; 132B: 23-30.

11. Guibourdenche M, Collatz E, Courvalin P, et al. Recherche de bêta-lactamase chez Neisseria gonorrhoeae par une adaptation en gel de la méthode iodométrique. Ann Biol Clin (Paris) 1983;41:209-11.

12. Catlin BW. Characteristics and auxotyping of Neisseria gonorrhoeae. In: Bergan T, Norris JR, eds. Methods in microbiology. Vol 10. London, New York, San Francisco: Academic Press, 1978:345-81.

13. Sandstrom E, Danielson D. Serology of Neisseria gonorrhoeae: classification by co-agglutination. Acta Pathol Microbiol Immunol Scand [B] 1980;88:27-38.

14. Sandström EG, Knapp JS, Buchanan TB. Serology of Neisseria gonorrhoeae: W-antigen serogrouping by coagglutination and protein I serotyping by enzyme-linked immunosorbent assay both detect protein I antigens. Infect Immun 1982; 35:229-39.

15. Georges AJ, Georges MC, Saluzzo JF, et al. Auxotypes et sensibilité à 5 antibiotiques de souches de Neisseria gonorrhoeae isolées en République Centrafricaine en 1980 et 1981 Bull Soc Pathol Exot Filiales 1982; 75:352-9.

16. Odugbemi TO, Brown ST, Biddle J, et al. Plasmid profile, serogrouping, and auxotyping of Neisseria gonorrhoeae isolates from Africa. British Journal of Venereal Diseases 1983; 59:41-3.

17. Handsfield HH, Sandström EG, Knapp JS, et al. Epidemiology of penicillinase-producing Neisseria gonorrhoeae infections. Analysis by auxotyping and serogrouping. $N$ Engl $J$ Med 1982; 306: 950-4.

18. Riou JY, Guibourdenche M. Marqueurs épidémiologiques des Neisseria. Pathol Biol (Paris) 1982;30: 163-75.

19. Perine PL, Totten PA, Knapp JS, Holmes KK, Bentsi C, Klufio CA. Diversity of gonococcal plasmids, auxotypes and serogroups in Ghana. Lancet 1983; i: 1051-2.

20. Buchanan TM, Hildebrandt JF. Antigen-specific serotyping of Neisseria gonorrhoeae: characterization based upon principal outer membrane protein. Infect Immun 1981;32:985-94.

21. Tam MR, Buchanan TM, Sandström EG, et al. Serological classification of Neisseria gonorrhoeae with monoclonal antibodies. Infect Immun 1982;36: 1042-53.

22. Bygdeman S, Kallings I, Danielsson D. Serogrouping and auxotyping for epidemiological study of beta-lactamase producing Neisseria gonorrhoeae strains isolated in Sweden. Acta Derm Venereol (Stockh) 1981;61:329-34.

23. Riou JY, Yvert F, Labidi A, et al. Apparition au Gabon de l'association du plasmide de $3 \cdot 2$ Megadaltons (Mdal) codant pour la bêta-lactamase avec le plasmide conjugatif de $24 \cdot 5$ Mdal chez Neisseria gonorrhoeae. Médecin et Maladies Infectieuses 1983; 13:798-800. 